\title{
Starling resistor and Miyazaki syndrome
}

\author{
Riccardo Caruso $^{1}$ (D) Alessandro Pesce $^{2} \cdot$ Venceslao Wierzbicki $^{3}$
}

Received: 5 August 2016 / Accepted: 11 August 2016/Published online: 19 August 2016

(C) Springer-Verlag Berlin Heidelberg 2016

\section{Dear Editor,}

We read with great interest the article "The cerebral venous system and the postural regulation of intracranial pressure: implications in the management of patients with cerebrospinal fluid diversion" of Kaveh Barami and Sandeep Sood [1]. The authors describe in detail the relationships that exist between the pressure of the CSF and the intra-extracranial venous circulation in different postural and clinical conditions. What is particularly interesting about this article is the explanation of the regulatory mechanism of the head blood outflow when a CSF shunt is in place. The lack of the mechanism known as Starling resistor to limit the intracranial venous depletion in postural changes, in case of malfunctioning shunt, can be identified as primarily responsible for Miyazaki syndrome, [2] recently described by us. This syndrome is characterized by intracranial hypotension, myelopathy caused by engorgement of the cervical vertebral venous plexus, and the absence of orthostatic headache, found only in patients with overdrainage by ventriculoperitoneal shunt malfunction. In our article, we hypothesized that the rise of the venous outflow is likely to cause, in patients who have CSF hypotension, venous congestion causing myelopathy. The lack of Starling resistor in patients with CSF shunt perfectly matches our theory. The relative rarity of Miyazaki syndrome compared to the number of cases of overdrainage can therefore be explained by the concurring rarity of people who present a predominantly venous drainage in intraspinal vertebral circulation. All patients affected by M syndrome had the CSF shunt without an anti-siphon system, the importance of which was largely outlined by Berami and Sood especially in regard to the prevention of damage due to chronic CSF depletion.

\section{Compliance with ethical standards}

Conflict of interest The authors declare that they have no conflict of interest.

\section{Reference}

1. Barami K, Sood S (2016) The cerebral venous system and the postural regulation of intracranial pressure: implications in the management of patients with cerebrospinal fluid diversion. Childs Nerv Syst 32(4):599-607. doi:10.1007/s00381-015-3010-1

2. Caruso R, Wierzbicki V, Marrocco L, Pesce A, Piccione E (2015) A poorly known cerebrospinal fluid shunt complication: Miyazaki syndrome. Word Neurosurg 84(3):834-838. doi:10.1016/j. wneu.2015.04.030
Riccardo Caruso

riccardo.caruso@uniroma1.it

1 Department of Neurology and Psychiatry, Sapienza Rome University, Via Pietro da Cortona 1, 00196 Rome, Italy

2 Neurosurgical Division Sant'Andrea Hospital, Sapienza Rome University, Via di Grottarossa 1035/1039, 00189 Rome, Italy

3 Neurosurgical Division of the Rome Army Medical Center, Via S. Stefano Rotondo 4, 00184 Rome, Italy 